\title{
La relación comercial de México con Estados Unidos y China en el siglo xxl: efectos en la integración local del aparato productivo mexicano
}

Mexico's trade relationship with the United States and China in the twenty-first century: effects on the local integration of the Mexican productive apparatus

\section{Samuel Ortiz Velásquez *}

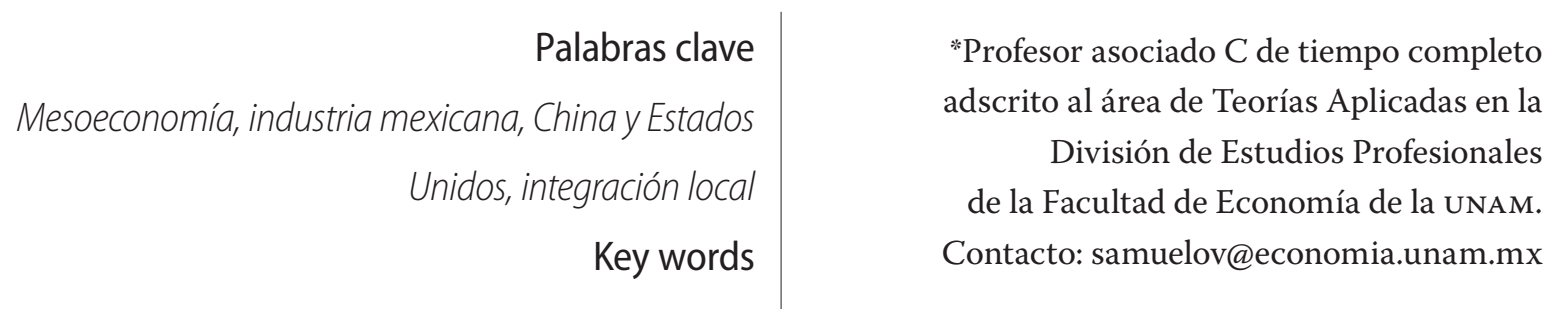

Mesoeconomics, Mexican industry, China and the

United States, local integration

JEL

L60, F15, L16 Y 014

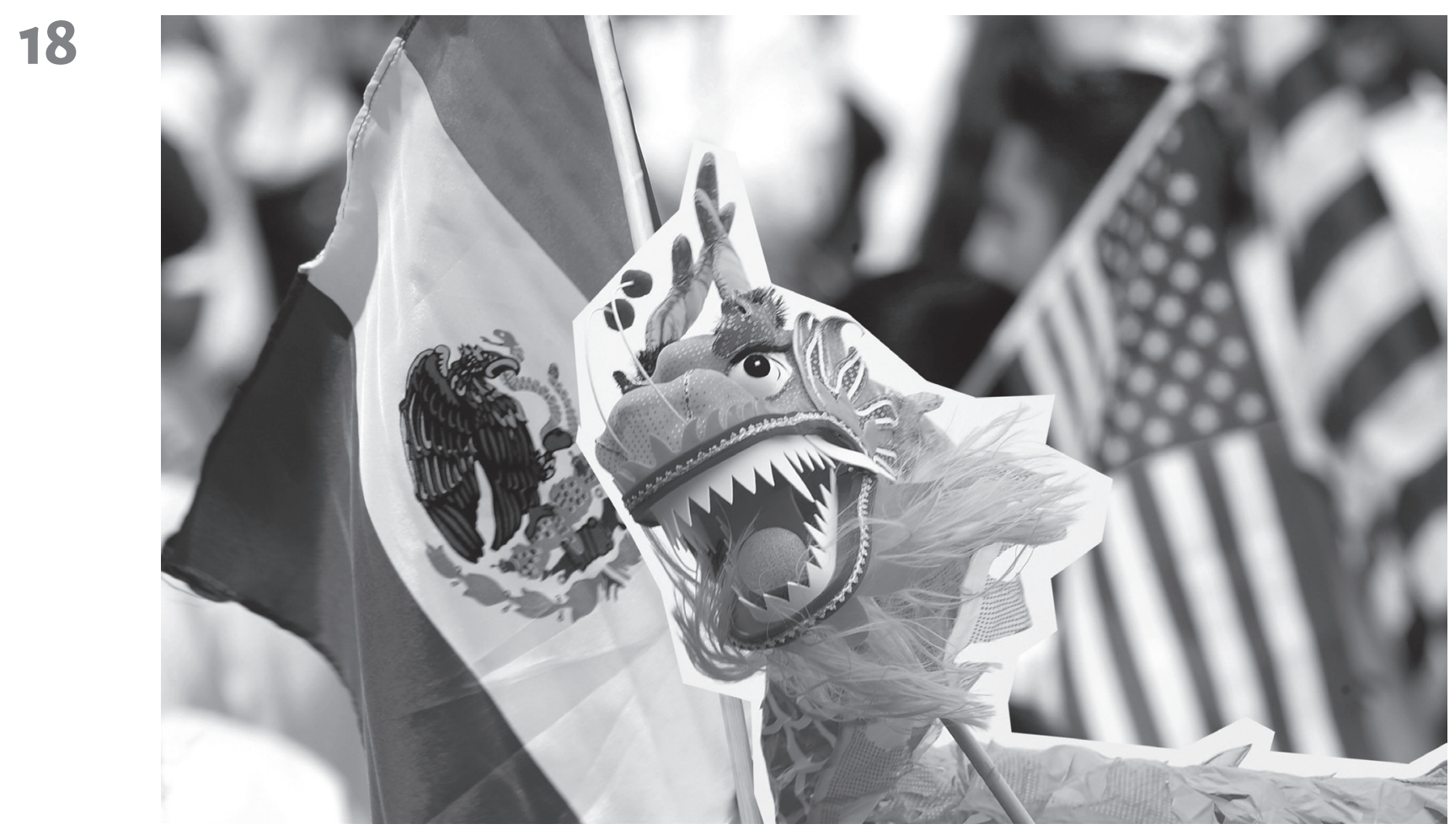

ECONOMÍA INFORMA | 407 | NOVIEMBRE-DICIEMBRE 2017 | 
Samuel Ortiz Velásquez | La relación comercial de México con Estados Unidos y

China en el siglo XXI: efectos en la integración local del aparato productivo mexicano

\section{Resumen}

El artículo estudia la integración comercial de México con Estados Unidos y China y sus efectos en la integración local del aparato productivo mexicano. Se presenta información para 220 clases manufactureras, cubriendo el periodo 2003-2014. Con base en diferentes tipologías, se muestra cómo el ingreso de China a la omc en 2001 profundizó la dependencia importadora del aparato productivo mexicano, tanto en las industrias exportadoras como en las industrias orientadas al mercado nacional. Entre otras cosas se concluye que China ha desplazado directamente a los Estados Unidos como principal importador en 152 industrias que operan en México, de las cuales 62 están orientadas a las exportaciones y destinan el $87 \%$ de ellas a los Estados Unidos. Ello revela la emergencia de una compleja organización industrial que se ha establecido entre las citadas industrias con China y con Estados Unidos, con efectos adversos en encadenamientos productivos locales. Las 90 industrias restantes presentan fuertes encadenamientos productivos locales y son relevantes en generación de empleo, en éstas, la entrada masiva de importaciones chinas, ha desplazado inversión, empleo y proveeduría local. La política macroeconómica y mesoeconómica ha contribuido a la peculiar integración local-global del aparato productivo mexicano.

\section{Abstract}

The article studies the commercial integration of Mexico with the United States and China and its effects on the local integration of the Mexican productive apparatus. Information is presented for 220 industrial classes, covering the period 2003-2014. Based on different typologies, it is shown how China's entry into the WTO in 2001 deepened the import dependence of the Mexican manufacturing apparatus, both in the export industries and domestic market industries. Among other outcomes, China has directly displaced the United States as the main importer in 152 industries operating in Mexico, of which 62 are export oriented and $87 \%$ of them are destined for the United States. This phenomenon reveals the emergence of an industrial organization that has been established between Mexican industries with China and the United States, with adverse effects in local productive linkages. The remaining 90 industries have strong local production chains and are relevant in employment generation; in these industries, the massive entry of Chinese imports has displaced investment, employment and local supply. Current macroeconomic and mesoeconomic policy has encouraged this special kind of local-global integration.

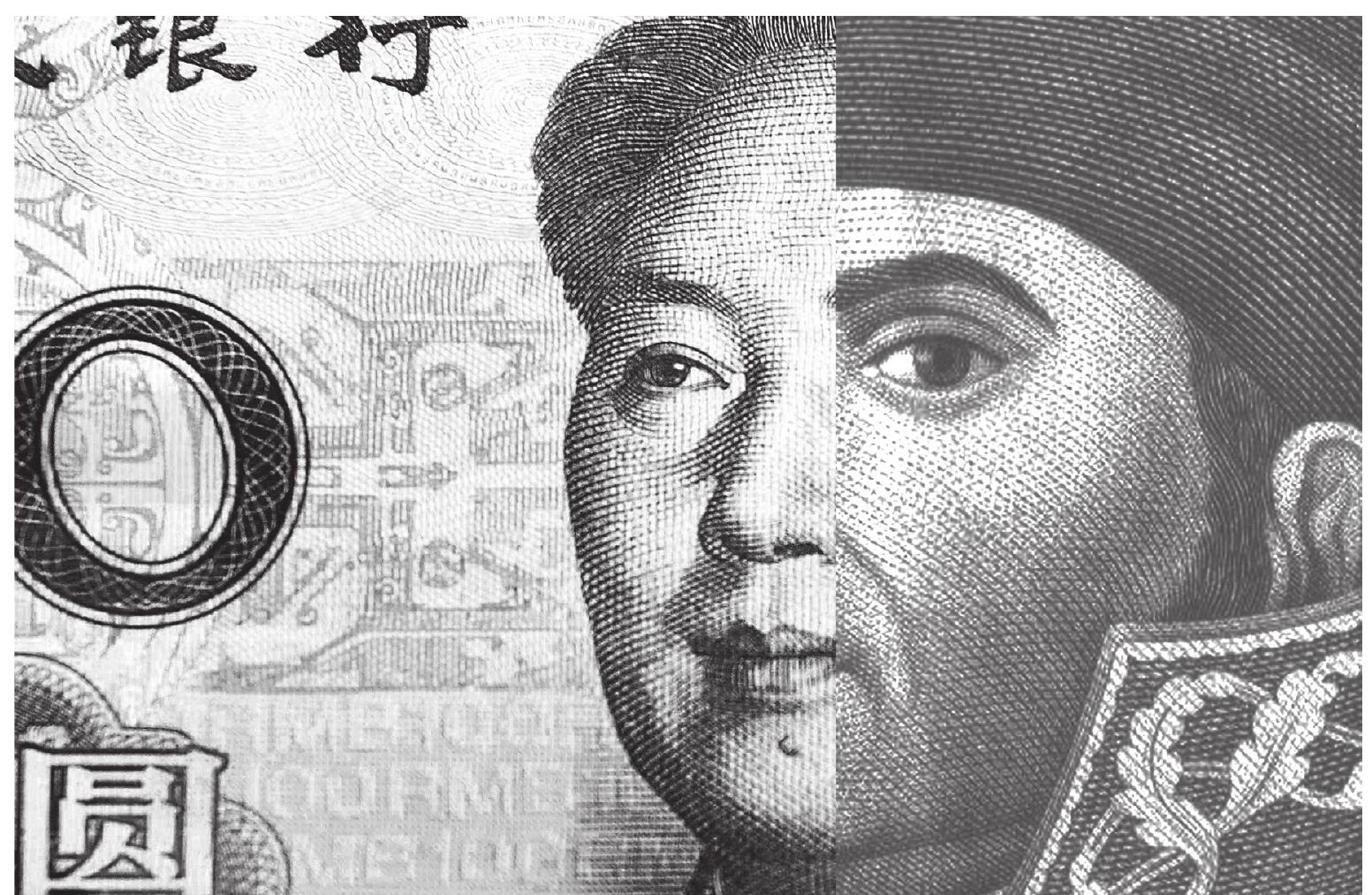




\section{Introducción}

La industria manufacturera mexicana atraviesa por una nueva etapa de desaceleración desde 2001, ello se ha reflejado en una tasa de crecimiento promedio anual (TСРA) entre 20012015 de $1.4 \%$, que representó una quinta parte comparada con las TCPA de $6.9 \%$ del periodo 1960-1981 (INEGI, 2017). Una lectura a través de segmentos y procesos específicos (Gereffi, 2001; Dussel Peters, 2003b) y no de sectores económicos, permite apuntar a que la conducta de la industria mexicana se puede explicar a partir de su tipo especial de integración comercial a los procesos de segmentación internacional de las cadenas productivas contemporáneos y las respuestas territoriales a dicha dinámica.

En los procesos descritos, Estados Unidos -especialmente desde 1994 con la entrada en vigor del Tratado de Libre Comercio de América del Norte (TLCAN)- y China -desde 2001 con su ingreso a la Organización Mundial del Comercio (OMC)-, han sido dos actores clave que han empujado el tipo especial de integración comercial de las manufacturas mexicanas.

Partiendo del creciente proceso de desintegración comercial del TLCAN y una progresiva presencia de las importaciones de China en el mercado manufacturero mexicano desde 2000 (Dussel Peters y Ortiz Velásquez, 2016), el objetivo del artículo consiste en examinar a nivel de la clase industrial, los efectos económicos que tales procesos han tenido sobre las industrias mexicanas, en términos de integración local en: inversión, empleo y encadenamientos productivos internos. En breve, la discusión contribuye y profundiza en el debate reciente sobre el valor agregado doméstico contenido en el comercio exterior. ${ }^{1}$

1 Algunos estudios apuntan que la participación del valor agregado contenido en las exportaciones mexi-
Por razones de disponibilidad de la información, el ejercicio empírico considera el periodo 2003-2014 y presenta la conducta de 220 industrias manufactureras. El aporte consiste en identificar los rasgos que tipifican a las industrias ganadoras y perdedoras de ambos procesos, así como sus grados de integración local. La temática es relevante pues contribuye al debate público sobre los efectos del TLCAN en la planta productiva mexicana, en el contexto de su actual renegociación. Se concluye con algunas propuestas destinadas a la reactivación del aparato productivo mexicano en el corto plazo, a partir de la identificación de un grupo de industrias generadoras de empleo y altos encadenamientos productivos internos.

El documento se estructura en cuatro apartados. En la primera parte se presentan un conjunto de determinantes de organización industrial, macroeconómicos y mesoeconómicos, que contribuyen a explicar el estilo de integración comercial de las industrias mexicanas particularmente desde mediados dela década de los ochenta y en los años que han seguido a la firma del TLCAN. La segunda sección describe la metodología utilizada para el ejercicio empírico. La tercera sección presenta los resultados del ejercicio empírico. En la última parte se presentan las conclusiones.

\section{Determinantes de organización industrial, macroeconómicos y mesoeconómicos}

El apartado se subdivide en dos secciones. Primero se presentan aspectos de organización industrial que permiten comprender la participación del aparato productivo mexicano en la dinámica de las Cadenas Globales de Valor

canas es cercana al 70\% (Timmer et al. 2015 con base en WIOD y Fujii y García 2016 con base en OCDE-TIVA), mientras otros apuntan a que el coeficiente es muy inferior (50\%) como en Koopman et al. (2014). 


\section{a participación relativa de las economías subdesarrolladas en el producto y las exporta- ciones manufactureras mundiales no es sinónimo de industrializa- ción, muy al contrario, puede ocul- tar una inserción comercial débil}

(CGV); en segundo lugar, se discuten diversas variables macroeconómicas y mesoeconómicas inscritas en el funcionamiento de la modalidad de crecimiento vigente y sus efectos en la integración de la industria mexicana.

La fragmentación espacial del proceso productivo profundizada desde finales de la década de los setenta y principios de los ochenta del siglo $\mathrm{xx}$, descrito adecuadamente por Gereffi (2001), ha surtido impactos a nivel local, en la medida que ha empujado a industrias locales a competir por participar en segmentos del proceso productivo, todo lo cual ha tenido implicaciones en términos de apropiación de valor agregado (inversión y salarios) y eslabonamientos productivos. Por ejemplo, en la cadena autopartes-automotriz o la electrónica, los segmentos de investigación y desarrollo pueden apropiarse de un valor agregado muy superior, al apropiado por los segmentos de ensamble de partes/componentes.

Al respecto la evidencia señala que las economías desarrolladas continúan concentrando y desarrollando segmentos de alta apropiación de valor agregado y trabajo de calificación alta, mientras transfieren al resto de las economías segmentos de baja apropiación de valor agregado y trabajo de calificación media y baja (Timmer, et al., 2014). En breve, las tendencias anteriores son relevantes cuando se les confronta con las tesis clásicas de industrialización de Kaldor y Prebisch. Pues desde una perspectiva de segmentos y procesos la tercerización en las economías desarrolladas está muy vinculando con el crecimiento de diferentes actividades cruciales para la industria (v.gr., investigación y desarrollo, diseño, etc.), pero ello no necesariamente implica que tales economías se estén desindustrializando, muy al contrario, puede significar que participan en segmentos de mayor apropiación de valor agregado. De manera análoga, la participación relativa de las economías subdesarrolladas en el producto y las exportaciones manufactureras mundiales no es sinónimo de industrialización, muy al contrario, puede ocultar una inserción comercial débil basada en la participación en segmentos de CGV de baja apropiación de valor agregado. Una conclusión preliminar es que las tesis clásicas de industrialización deben ampliarse en función de las realidades contemporáneas descritas.

El proceso de segmentación internacional es conducido por empresas dominantes, usualmente trasnacionales (ET). De hecho, UNCTAD (2011) ha estimado que cerca del $80 \%$ de las exportaciones mundiales están vinculadas a las redes internacionales de producción de las ET. Las ET se pueden situar en la esfera de la producción -en el caso de las cadenas productivas dirigida al productor (СРP), que involucra a industrias como la automotriz, aeronáutica, computadoras y maquinaria pesada-, o bien, en la esfera de la circulación -en el caso de las cadenas dirigidas al comprador (СРC) que involucra industrias como vestido, calzado, juguetes, que son gobernadas por grandes detallistas (como Walmart), comercializadores (como Nike) y fabricantes de marca (como Zara) (Gereffi 2001). 


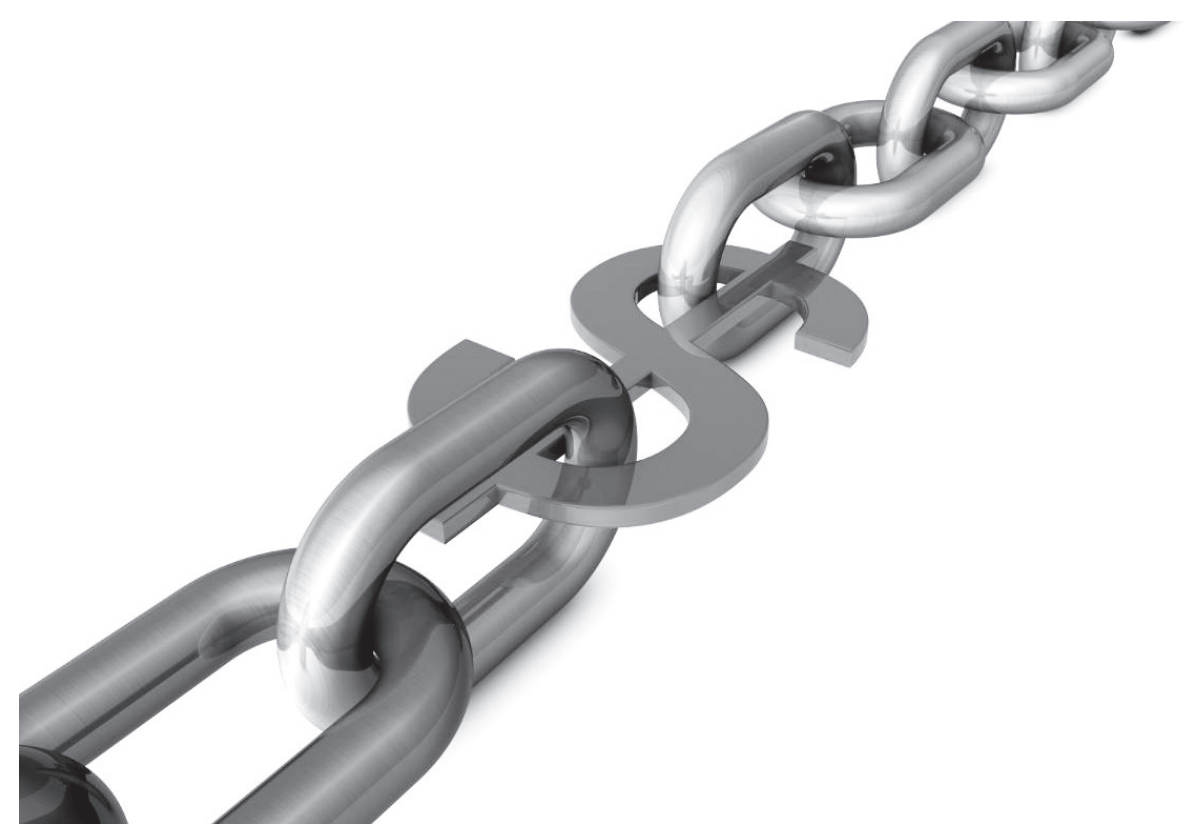

El punto a subrayar es que las ET dominantes en la cadena, ejercen su poder de mercado sobre otros eslabones, con cargo a barreras a la entrada derivadas de su tamaño (o naturales) o bien estratégicas (o artificiales), todo lo cual les permite elevar su rentabilidad:

i) En las CPP los principales vínculos de la red se dan vía la Inversión Extranjera Directa (IED) (Gereffi, 2001) y predominan las barreras naturales a nuevos entrantes nacionales. Las filiales de las ET usualmente llegan a industrias altamente concentradas, tanto ellas como los sectores en que participan presentan altos niveles de densidad de capital, productividad y rentabilidad (Fajnzylber 1980; Valenzuela, 2014; Ortiz Velásquez 2015).

ii) En el caso de las СPC predominan las barreras artificiales y los vínculos principales en la red se dan vía el comercio (Gereffi, 2001) y las formas no accionariales de la producción (FNA) basada en la subcontratación (UNCTAD 2011). De hecho, es difícil observar que una CPC invierta en los territorios con los que se vincula. Como usualmente buscan eslabonamientos intra e inter empresa con economías subdesarrolladas, donde existen sectores de pequeña pro- ducción mercantil, de muy baja intensidad de capital, éstas resultan fácil presa del poder de mercado que ejerce la empresa dominante por la vía de precios de compra y condiciones de venta. Todo lo cual, se convierte en un mecanismo que le permite a la ET y su eslabón, elevar su rentabilidad.

En suma, el cambio en el estilo de relacionamiento de las ET con los territorios, a través del proceso de segmentación de la cadena productiva, obedeció a criterios microeconómicos de rentabilidad. Con ello, su conducta en los territorios de destino es una proyección de las tendencias generales que ha caracterizado su expansión mundial. Otros procesos globales han contribuido a dicho fenómeno como: i) una creciente flexibilización de la demanda; ii) la mejora y reducción de costos de los medios de transporte; iii) el crecimiento de la subcontratación a nivel internacional; iv) la reemergencia de China y su creciente presencia en los mercados de manufacturas mundiales desde finales de la década de los setenta y particularmente desde 2001 con su ingreso a la omc. Agreguemos, los cambios globales ocu- 
rrieron en el contexto de un nuevo modelo de crecimiento en buena parte de las economías desarrolladas y subdesarrolladas, usualmente denominado neoliberal.

Una tesis central del enfoque de las Cadenas Globales de Valor es que, para lograr el desarrollo industrial local, sólo se requiere de una vinculación selectiva con las empresas líderes/ dominantes más importantes de una industria global, mediante, v.gr., el ascenso industrial (Gereffi, 2001). En nuestra opinión, la respuesta de los territorios a los fenómenos globales descritos determinará su grado de integración local. Efectivamente, como en su momento señaló Fajnzylber (1980), la responsabilidad de introducir las rectificaciones necesarias al estilo de crecimiento es interna y no puede delegarse a un agente como la ET cuya racionalidad obedece a criterios micro. Algunos autores han discutido éste amalgama global-local, por ejemplo, en años recientes, se ha trabajado el concepto "competitividad sistémica" (Esser, Hillebrand, Messner y Meyer-Stamer, 1999: 40). El concepto es un marco metodológico para el análisis y la política económica. Desde ésta perspectiva, para que un territorio eleve su competitividad se requiere de la interacción dinámica y compleja de esfuerzos que operan en diferentes niveles analíticos: el nivel micro; el nivel meso (de las políticas, instituciones específicas y redes inter empresa); el nivel macro; el nivel meta (de variables lentas como las estructuras socio-culturales, el orden y la orientación de la economía y la capacidad de los actores sociales para formular estrategias).

Con base en el citado enfoque, un examen del caso mexicano apunta a la existencia de una débil competitividad sistémica vinculada al acelerado proceso de reformas estructurales y de apertura, que explicaría en parte el tipo de integración del aparato productivo a la dinámica glocal descrita, a partir del examen de algunos determinantes de la acumulación.

En el ámbito macroeconómico destaca el comportamiento del tipo de cambio real. Como observaron Prebisch y Thirlwall en su momento, en las economías subdesarrolladas la producción interna de bienes de capital es reducida, por lo cual, el grueso de ellas se sustenta en importaciones. Ello impone una restricción al crecimiento por el lado de la demanda, pues sus divisas por exportaciones (i. e., su capacidad para importar) resultan insuficientes para financiar las importaciones de bienes de inversión necesarias para elevar el crecimiento del producto. El importante peso relativo de los bienes de capital importados en la oferta total de bienes de capital, otorga un papel relevante al tipo de cambio real en las decisiones de inversión. Bien se puede sostener que para el caso de la economía mexicana los periodos recurrentes de apreciación del tipo de cambio real desde finales de la década de los ochenta han estimulado la entrada de importaciones y ello ha tenido efectos diferenciados en las industrias. El efecto ha sido positivo para las industrias exportadoras y dependientes de importaciones de insumos intermedios (piénsese en la electrónica) y las industrias intensivas en capital, considerando el alto contenido importado de la oferta de inversión en maquinaria y equipo (inversión activa). ${ }^{2} \mathrm{El}$ efecto ha sido negativo para el grueso de las industrias orientadas al mercado nacional, especializadas en la producción de bienes de consumo personal y/o productoras de bienes intermedios; pues las importaciones desplazan a proveedores industriales nacionales, con efectos adversos en términos de encadenamientos.

2 La participación relativa de la inversión activa importada en la inversión activa total pasó de $30 \%$ a $68 \%$ entre 1983-2016 (INEGI 2017). 
Con base en lo anterior, bien se podría hablar de un efecto neto negativo. Por ejemplo, se ha demostrado que entre 1994-2012, por cada aumento de un punto porcentual en las compras de insumos importados por parte de las principales industrias exportadoras, la inversión de sus principales proveedoras nacionales se reduce en el largo plazo en 0.133 . El efecto negativo supera al efecto positivo sobre la inversión de las proveedoras derivado de la dinámica de las exportaciones, con un coeficiente de largo plazo de 0.056 (Ortiz V., 2015).

La dinámica de la demanda interna (el acelerador de Harrod) al modificar el grado de aprovechamiento de la capacidad productiva es un determinante de la inversión. Por otro lado, el problema del acceso a financiamiento es una de las desventajas más importantes para las empresas de menor tamaño en un contexto de monopolio. Con base en la experiencia mexicana, bien se puede sostener que la debilidad de la demanda interna y el racionamiento del crédito productivo desde mediados de la década de los noventa, han contribuido a obstaculizar la permanencia y/o desarrollo de industrias proveedoras nacionales, impactando adversamente en la conducta del aparato productivo mexicano. De hecho, en el trabajo citado, se ha demostrado que, por cada aumento en un uno por ciento en la tasa de crecimiento del producto agregado en 151 clases industriales, su inversión fija bruta crece en el largo plazo a una tasa de $0.76 \%$, convirtiendo al acelerador en el determinante central y sistemático de la inversión. Al tiempo que, por cada aumento en un punto porcentual en el crédito comercial dirigido a la manufactura, la inversión crece en $0.22 \%$. Los efectos han sido más grandes para el grueso de manufacturas orientadas al mercado nacional.

En el nivel meso, la política industrial y comercial en México desde mediados de la década de los ochenta, ha sido coherente con las

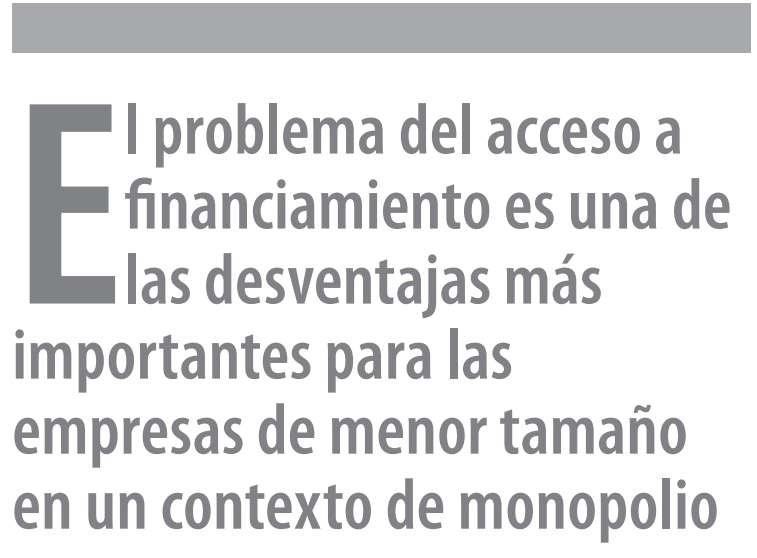

reformas de apertura, la adhesión de México a la OMC y la firma del TLCAN, éstas últimas, instituciones que imponen fuertes restricciones al fomento industrial en México. El enfoque horizontal predominante de política industrial (Dussel Peters 2000) formalizado a partir del Programa Nacional de Modernización Industrial y del Comercio Exterior 1990-1994, significó entre otras cosas el desmantelamiento de programas, instrumentos e instituciones públicas de fomento industrial (un examen se encuentra en Moreno-Brid 1999; Dussel Peters 2000; Ortiz Velásquez 2015). De hecho, desde 2000 no se identifican programas de política industrial stricto sensu.

En el nivel meso también destacan los programas de importaciones temporales para su posterior exportación (ITE) (Dussel Peters, 2003a), altamente funcionales a la implementación desde 1994 del TLCAN. Tales programas -desde finales de 2006 opera el Programa de Fomento de la Industria Manufacturera, Maquiladora y de Servicios de Exportación (Immex)-, son instrumentos que permiten importar temporalmente los bienes y servicios utilizados para la exportación o a la prestación de servicios de exportación, sin cubrir el pago del impuesto general de importación, del IVA y en su caso, de 
las cuotas compensatorias. Es decir, los procesos ITE han generado importantes incentivos fiscales y junto con los periodos de apreciación cambiaria, han contribuido al debilitamiento de los encadenamientos productivos con el mercado nacional, vía el fuerte estímulo a las importaciones prescindibles y no prescindibles. $V . g r$., desde 1993 casi $70 \%$ de las exportaciones mexicanas dependieron de dichos programas (Ortiz Velásquez, 2015). A ello se agrega que, no obstante, la nueva generación de programas sectoriales horizontales desde 1998 que impactaron sobre costos y precios relativos clave para la industria, las industrias altamente exportadoras como la automotriz-autopartes, han sido objeto de programas especiales de apoyo y ello puede explicar que la automotriz sea de las pocas industrias exportadoras que ha logrado mejorar sus encadenamientos productivos internos con el mercado nacional (Ortiz Velásquez 2015).

En un esfuerzo de síntesis, bien se pudiera apuntar a que la política macroeconomía y la política mesoeconómica en la etapa neoliberal desde la década de los ochenta, se ha alineado (y se ha hecho funcional) a los requerimientos de las Cadenas Globales de Valor y sus ET, todo lo cual, ha jugado en contra del mercado mexicano nacional. Como se apuntó en la introducción, Estados Unidos y China han sido dos actores clave del proceso. Por una parte, la economía mexicana presenta desde 2001 un superávit comercial con EeUU que se ha multiplicado por más de seis veces y un abultado y creciente déficit comercial con China que se multiplicado por casi 20 veces (UN COMTRADE 2017). ${ }^{3}$

3 Destaca que la relación comercial de China con México ha sido de tipo interindustrial, altamente concentrada y con una tendencia a la "reprimarización" de las exportaciones mexicanas (Dussel Peters y Ortiz Velásquez, 2016).

\section{Descripción de la metodología utilizada}

El presente apartado examina la conducta de las industrias mexicanas "ganadoras" y "perdedoras" del proceso de apertura y en concreto del tipo especial de organización industrial que se ha generado con Estados Unidos y con China.

Integración estadística. Se integró una serie estadística a nivel de clase industrial que abarca el periodo 2003-2014, con base en las Encuestas Industriales Anuales (EIA) de INEGI; montos de comercio exterior total y con Estados Unidos y China a ocho dígitos del Sistema Armonizado de Designación y Codificación de Mercancías (SA) recopilado por INEGI -con alrededor de 9,983 fracciones que integran a la manufactura mexicana-, y estadísticas de IED de la Secretaría de Economía de México. La integración estadística se logró con el uso de la tabla de correlación del "Sistema de Clasificación Industrial de América del Norte (sCIAN) 2002-SCIAN 2007" (INEgi, 2016a) y la “Tabla de Correlación entre la Tarifa de la Ley de los Impuestos Generales de Importación y de Exportación y el Sistema de Clasificación Industrial de América del Norte tigie - scian" (INEGI, 2016b).

Como se ha señalado en un documento previo (Ortiz Velásquez, 2015), el proceso de homologación no es trivial, pues el primer instrumento es un medio que permite vincular teóricamente los clasificadores, i.e., hacerlos equiparables a nivel conceptual, pero resulta insuficiente para permitir la comparación de datos stricto sensu, pues no es posible en todos los casos obtener valores en forma directa para cada una de las partes en que se divide una categoría de actividad del scian cuando es contrastada por otro indicador y viceversa. Además, las EIA han atravesado por dos cambios en la metodología y ello implica entre otras 


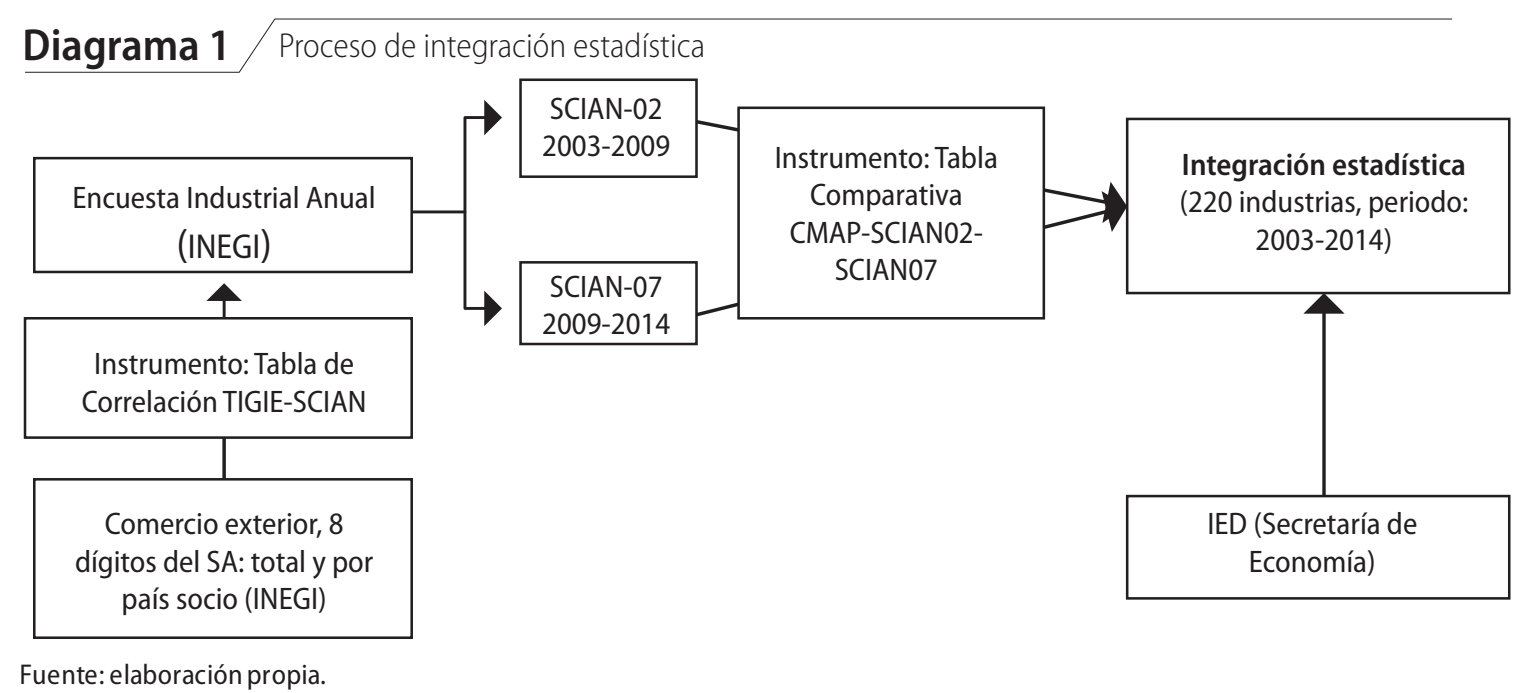

cosas, cambios en el número de establecimientos y su representatividad. No obstante, a pesar de su carácter teórico, las tablas son un instrumento de apoyo indispensable que sirve como base para lograr la mayor correspondencia posible entre los datos estadísticos recolectados.

El resultado fue la integración de una serie que da cuenta de estadísticas de producción, comercio exterior (con Estados Unidos y China) e IED para 220 clases industriales mexicanas durante 2003-2014, en miles de pesos corrientes y constantes de 2008 (ver diagrama 1).

Taxonomía de las industrias mexicanas. A partir de la serie, se construyó una matriz de interacciones competitivas entre los dos principales proveedores de la industria mexicana: EEUU y China, con base en la metodología de Lall y Weiss (2005) y aplicada en años recientes por Dussel Peters y Gallagher (2013) y Dussel Peters y Ortiz Velásquez (2016) (ver cuadro 1$){ }^{4}$

4 Lall y Weiss examinan la evolución de las exportaciones de China y ALC al resto del mundo y al mercado estadounidense y buscan probar la emergencia de una mayor competencia china en segmentos que registran un aumento de sus exportaciones, a medida que decrece la penetración de los productos de América Latina.
El procedimiento consistió en el calculó de la participación relativa de las importaciones chinas y estadounidenses en las importaciones totales de las manufacturas mexicanas entre 2003 y 2014 y su diferencia en puntos porcentuales. A partir de las cuales, se obtuvieron las principales interacciones competitivas en el mercado mexicano. ${ }^{5}$

Para evaluar la integración comercial de las industrias mexicanas con EEuU y China según su orientación (mercado nacional o exportaciones), se clasificó cada subgrupo de interacciones según el destino principal de sus ventas: el mercado interno o el mercado externo, ello en función del comportamiento del coeficiente de exportaciones promedio ponderado de la manufactura total $\left(v x_{M}\right)$ para el periodo 20032014. El coeficiente se define como la participación de las exportaciones en la producción bruta total (Рвт). ${ }^{6}$ El resultado fue la confor-

5 Cuando la participación relativa de las exportaciones china en las manufacturas mexicanas aumenta, a medida que la participación relativa de las exportaciones de EeUu en esas mismas industrias disminuye, se puede hablar de que las importaciones chinas desplazan a las estadounidenses en el mercado mexicano.

6 Se consideran industrias orientadas a los mercados externos, aquellas que presenten un coeficiente de 
Samuel Ortiz Velásquez | La relación comercial de México con Estados Unidos y

China en el siglo XXI: efectos en la integración local del aparato productivo mexicano

Cuadro 1 Matriz de interacciones competitivas entre proveedores chinos y proveedores locales en las manufacturas mexicanas

\begin{tabular}{|c|c|c|c|}
\hline & & \multicolumn{2}{|c|}{ Participación relativa de China en el mercado mexicano } \\
\hline \multirow{7}{*}{$\begin{array}{l}\text { Participación relativa } \\
\text { de EEUu en el mercado } \\
\text { mexicano }\end{array}$} & & Aumenta & Disminuye \\
\hline & \multirow{4}{*}{ Aumenta } & $\begin{array}{l}\text { A. EEUu desplaza parcialmente a } \\
\text { China }\end{array}$ & C. eEuu desplaza a China \\
\hline & & $\begin{array}{l}\text { La participación de ambos países } \\
\text { crece, pero el incremento de EEUu es } \\
\text { mayor que el de China }\end{array}$ & \multirow{3}{*}{$\begin{array}{l}\text { La participación de EEUu crece, } \\
\text { mientras que la de China se reduce. } \\
\text { Ello puede indicar una relación cau- } \\
\text { sal, a menos que China ya perdiera } \\
\text { participación relativa en el periodo } \\
\text { anterior a } 2001\end{array}$} \\
\hline & & $\begin{array}{l}\text { B. China desplaza parcialmente a } \\
\text { EEUU }\end{array}$ & \\
\hline & & $\begin{array}{l}\text { La participación de ambos países } \\
\text { crece, pero el crecimiento de China } \\
\text { es más rápido que el de EEUU }\end{array}$ & \\
\hline & & D. China desplaza a EEuU & $\begin{array}{l}\text { E. Retirada de ambos, en favor de } \\
\text { terceros }\end{array}$ \\
\hline & Disminuye & $\begin{array}{l}\text { La participación de China aumenta } \\
\text { mientras que la de EEUu se reduce. } \\
\text { Ello puede indicar una relación cau- } \\
\text { sal, a menos que EEUu ya perdiera } \\
\text { participación antes del ingreso de } \\
\text { China a la omc }\end{array}$ & $\begin{array}{l}\text { Ambas partes pierden partici- } \\
\text { pación relativa en los mercados } \\
\text { de exportación en favor de otros } \\
\text { competidores }\end{array}$ \\
\hline
\end{tabular}

Fuente: elaborado con base en Lall y Weiss (2005).

mación de 11 subgrupos, que clasifica a las industrias según su orientación y su relación comercial con EevU y con China (diagrama 1).

Efectos sobre la economía mexicana. Con base en la tipología, se examinaron diferentes asociaciones cuantitativas y cualitativas entre las importaciones totales, chinas y estadounidenses y sus efectos en la integración local de las manufacturas mexicanas. En primer lugar, se describieron las principales interacciones competitivas resultantes de la tipología y las industrias que conforman a cada subgrupo. Posteriormente se presentan las principales características de los agrupamientos: sus participaciones relativas en indicadores de producción, empleo y acervos netos y; la mecánica del

exportaciones superior al coeficiente medio; se consideran industrias orientadas al mercado nacional aquellas que presentaron un coeficiente de exportaciones igual o menor al coeficiente medio. crecimiento en cada agrupamiento a partir de la evolución de los acervos de capital, la relación capital por trabajador (asociada al comportamiento del tamaño de planta y la concentración de capital); la productividad del trabajo y el crecimiento del producto agregado.

En segundo lugar, para examinar las asociaciones que se establecen entre comercio exterior e indicadores de integración local, se calcularon Coeficientes de Correlación de Pearson (CCP), que asociaron las tasas de crecimiento de indicadores de integración (producto, acervos y empleo) con el crecimiento de las exportaciones de eEuU y las importaciones chinas (pues con tales indicadores se verificaron las más fuertes asociaciones). ${ }^{7}$

7 El CCP es una medida de la relación lineal entre dos variables aleatorias cuantitativas y es independiente de la escala de medida de las variables. Su cálculo sobre un estadístico muestral denotado por $r_{x y}$ se define 


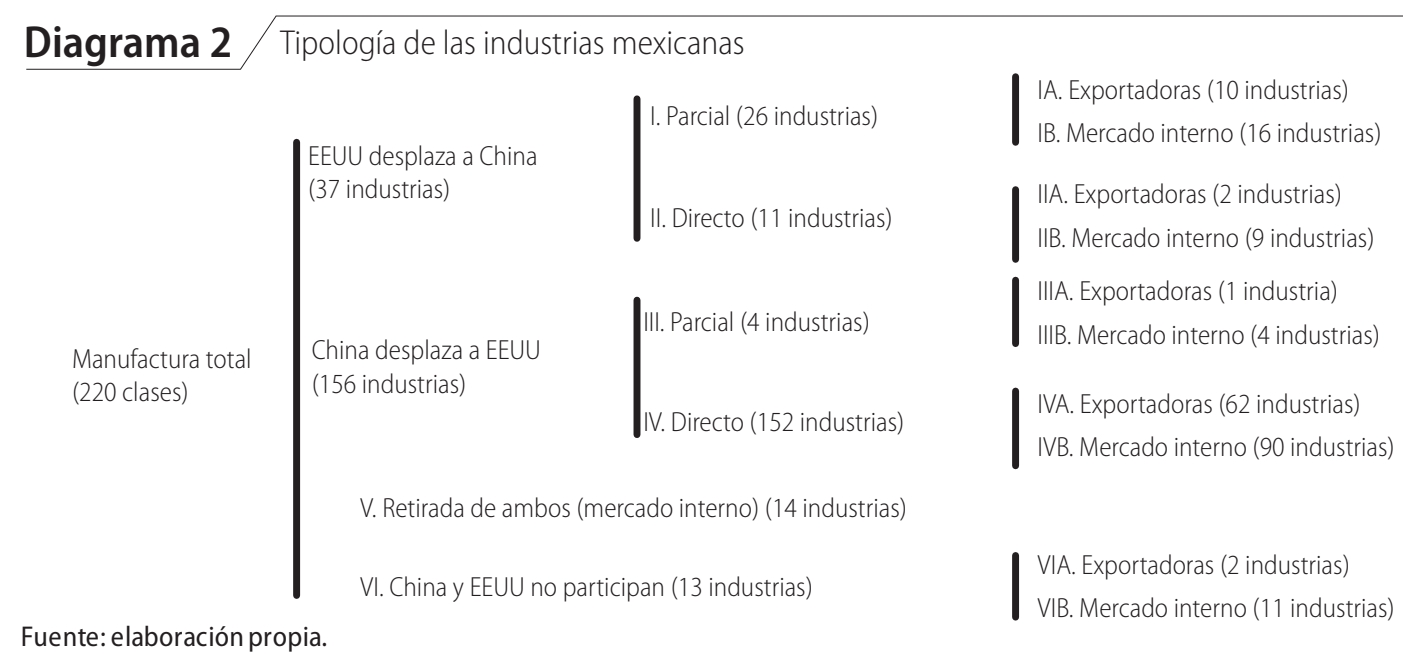

\section{La relación comercial China-México-Estados Unidos, implicaciones en la integración local del aparato productivo mexicano}

\subsection{Principales interacciones competitivas}

Se identificaron 152 industrias (que representaron el $69.95 \%$ del total de industrias), en las cuales la participación relativa de las importaciones manufactureras de EeUU se redujo en 25.12 puntos porcentuales entre 2003 y 2014, al tiempo que la participación relativa de las importaciones de China creció en casi 18 pun-

como:

$$
r_{x y}=\left(\Sigma x_{i} y_{i}\right) /(n-1) s_{x} s_{y}
$$

El valor del índice de correlación varía en el intervalo $[-1,1]$, indicando el signo el sentido de la relación: Si $r$ $=1$, existe una correlación positiva perfecta. El índice indica una dependencia total entre las dos variables denominada relación directa: cuando una de ellas aumenta, la otra también lo hace en proporción constante. Si $0<r<1$, existe una correlación positiva. Si $r$ $=0$, no existe relación lineal. Pero esto no necesariamente implica que las variables son independientes: pueden existir todavía relaciones no lineales entre las dos variables. Si $-1<r<0$, existe una correlación negativa. Si $r=-1$, existe una correlación negativa perfecta. El índice indica una dependencia total entre las dos variables llamada relación inversa: cuando una de ellas aumenta, la otra disminuye en proporción constante. tos. Por otra parte, el $3.37 \%$ de las exportaciones estadounidenses de manufacturas fueron desplazadas parcialmente por China. Con ello resulta que desde 2003 casi tres cuartas partes de las exportaciones estadounidenses de manufacturas al mercado mexicano habían sido desplazadas a nivel estadístico por China.

De forma análoga en 26 industrias las importaciones chinas se encuentran amenazadas parcialmente por las estadounidenses, pues en ellas que representaron el 9.90\% de las importaciones estadounidenses de manufacturas en 2014, la participación relativa de las importaciones de ambos países crece, pero crece más de prisa las de eeuu. Por otro lado, en 11 industrias que representaron $6.26 \%$ de las importaciones de Estados Unidos en 2014, se asiste a un desplazamiento parcial. Es decir, en 37 industrias las importaciones de eEvu han desplazado total o parcialmente a las importaciones chinas.

El examen a nivel de clases muestra que de las 152 industrias que han presentado un aumento en la participación relativa de las importaciones chinas en contra de las americanas, 90 de ellas operan fundamentalmente para el mercado nacional, mientras el resto de industrias está orientada a las exportacio- 
Samuel Ortiz Velásquez | La relación comercial de México con Estados Unidos y

China en el siglo XXI: efectos en la integración local del aparato productivo mexicano

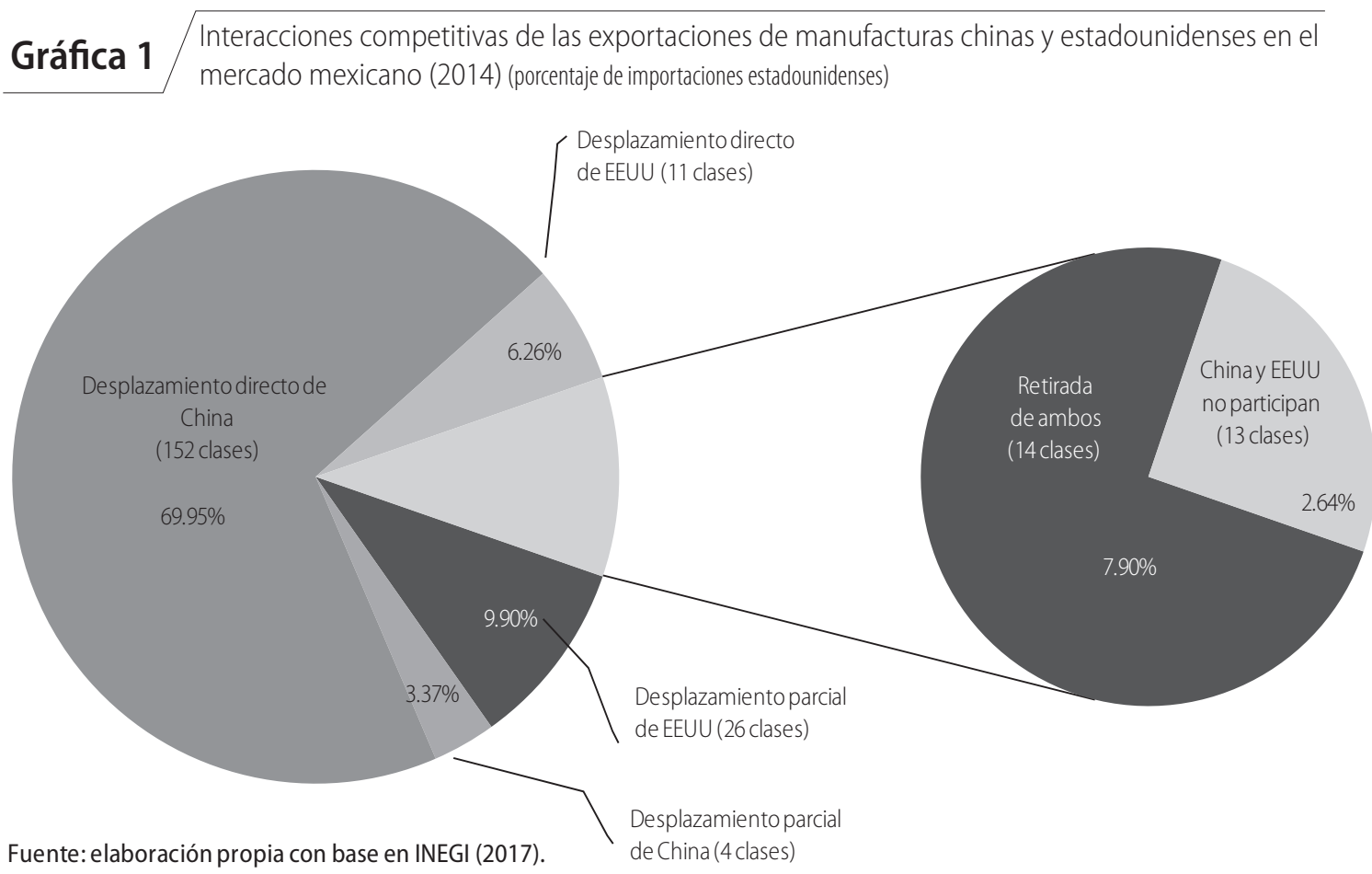

nes (ver cuadro 2). El subgrupo incluye a la totalidad de las industrias que integran a las cadenas de: hilo-textil-vestido y cuero-calzado y; casi a la totalidad de las industrias que conforman las cadenas: metal-mecánica; maquinaria y equipo; electrónica-eléctricos; autopartes-automotriz (con la excepción de automóviles-camionetas); química; papel, plástico-hule; minerales no metálicos y a la industria del juguete.

Del grupo de industrias que han atestiguado un aumento en la participación relativa de las importaciones estadounidenses, destaca el subgrupo de 10 industrias orientadas a las exportaciones y tipificadas como de desplazamiento parcial, pues entre otras incluye a la clase productora de automóviles-camionetas y la industria cervecera. Del agrupamiento de industrias orientadas al mercado nacional sobresale la industria refresquera y la refinación de petróleo y aceites y grasas lubricantes, éstas últimas, conforman a la industria petrolera.

\subsection{Características de los agrupamientos}

La industria mexicana presenta una alta concentración agregada según diferentes indicadores, v.gr., más del $80 \%$ del empleo generado por la industria entre 2003-2014 se ha concentrado en el subgrupo IV y concretamente en las 90 industrias que trabajan para el mercado nacional (ver cuadro 3). Éste subgrupo también ha sido significativo en términos de concentración del acervo de capital e IED. Destaca igualmente que las 10 industrias exportadoras que conforman al subgrupo I han concentrado más del 10\% del acervo de capital y más de una cuarta parte de la IED industrial; mientras, las 9 industrias orientadas al mercado nacional del subgrupo II han concentrado más del 25\% de las ventas industriales. Es decir, grosso modo, las industrias clave en términos de producción y generación de empleo han experimentado un crecimiento de las importaciones chinas en contra de las americanas. 
Cuadro 2. Tipología: industrias que conforman a cada subgrupo

\begin{tabular}{|c|c|c|c|c|}
\hline & \multicolumn{4}{|c|}{ EEUu desplaza a China (37 industrias) } \\
\hline & & I. Parcial (26 industrias) & & II. Directa (11 industrias) \\
\hline Exportadoras & 10 & $\begin{array}{l}\text { Alimentos (2/33); Bebidas (1/7: Cer- } \\
\text { veza); Química (1/18); Minerales no } \\
\text { metálicos (1/16); Metálicas básicas (1/9); } \\
\text { Electrónica (1/8); autopartes-automotriz } \\
\text { (3/14: Automóviles/cam; Carrocerías/ } \\
\text { remolques; Partes sist frenos) }\end{array}$ & 2 & $\begin{array}{l}\text { Bebidas ( } 2 / 7: \text { destiladas de agave; Otras } \\
\text { bebidas destiladas) }\end{array}$ \\
\hline \multirow[t]{2}{*}{ Mercado interno } & 16 & $\begin{array}{l}\text { Alimentos (6/33); Bebidas (1/7: Refres- } \\
\text { cos); Prendas ( } 1 / 6) ; \text { Madera (3/7); Papel } \\
\text { (2/7); Química (1/18); Maquinaria y } \\
\text { equipo (1/17); Otras (1/11) }\end{array}$ & 9 & $\begin{array}{l}\text { Alimentos (4/33); Bebidas (1/7); Madera } \\
\text { (1/7); Petróleo y carbón (2/3: Refinación } \\
\text { de petróleo; Aceites y grasas lubricantes); } \\
\text { Química (1/18) }\end{array}$ \\
\hline & \multicolumn{4}{|c|}{ China desplaza a eEuu (156 industrias) } \\
\hline & & III. Parcial (4 industrias) & & IV. Directo (152 industrias) \\
\hline Exportadoras & 1 & Maquinaria y equipo (1/17: agrícola) & 62 & $\begin{array}{l}\text { Insumos textiles (4/8); Textiles, excepto } \\
\text { prendas (3/6); Prendas (1/6); Cuero (1/5); } \\
\text { Madera (1/7); Química (7/18); Plástico y } \\
\text { hule (5/14); Minerales no metálicos (6/16); } \\
\text { Metálicas básicas (2/9); Metálicos (6/14); } \\
\text { Maquinaria y equipo (7/17); electrónica } \\
\text { (2/8, destaca: computadoras y perif); Eléc- } \\
\text { tricos (6/11); autopartes-automotriz (7/14: } \\
\text { camiones y tract; motores de gasolina y } \\
\text { sus p; equipo eléctrico y electrónico; partes } \\
\text { de sistemas de dirección y de suspensión; } \\
\text { partes de sistemas de transmisión; otras } \\
\text { partes; equipo ferroviario); Muebles (1); } \\
\text { Otras (2/11: juguetes) }\end{array}$ \\
\hline \multirow[t]{2}{*}{ Mercado interno } & 3 & $\begin{array}{l}\text { Impresión (1/2); Metálicas básicas (1/9: } \\
\text { Complejos siderúrgicos); Otras (1/11: } \\
\text { Velas y veladoras) }\end{array}$ & 90 & $\begin{array}{l}\text { Alimentos }(5 / 33) ; \text { insumos textiles }(4 / 8) ; \\
\text { textiles, excepto prendas }(3 / 6) ; \text { prendas } \\
(4 / 6) ; \text { cuero-calzado }(4 / 5) ; \text { madera }(2 / 7) ; \\
\text { papel }(5 / 7) ; \text { impresión }(1 / 2) ; \text { química } \\
(6 / 18) ; \text { plástico/hule }(8 / 14) ; \text { minerales no } \\
\text { metálicos }(7 / 16) ; \text { metálicas básicas }(4 / 9) ; \\
\text { metálicas }(8 / 14) ; \text { maquinaria y equipo } \\
(7 / 17) ; \text { electrónica }(5 / 8) ; \text { eléctricos }(5 / 11) ; \\
\text { autopartes-automotriz }(3 / 14) ; \text { muebles, } \\
\text { colchones }(2) ; \text { otras }(7 / 11)\end{array}$ \\
\hline & & V. Ambos sin cambios (14 industrias) & \multicolumn{2}{|r|}{ VI. EEUu y China no participan (13 industrias) } \\
\hline Exportadoras & 0 & & 2 & $\begin{array}{l}\text { Bebidas y tabaco ( } 2 / 7 \text { : beneficio de café y } \\
\text { de tabaco) }\end{array}$ \\
\hline Mercado interno & 14 & $\begin{array}{l}\text { Alimentos (7/33); bebidas y tabaco ( } 2 / 7 \text { : } \\
\text { ron; cigarros); petróleo y carbón ( } 1 / 3: \\
\text { productos de asfalto); química ( } 2 / 18: \\
\text { petroquímica; tinas impresión); metá- } \\
\text { licas básicas (1/9: desbastes primarios } \\
\text { y ferroaleaciones); transporte (1/14: } \\
\text { embarcaciones) }\end{array}$ & 11 & $\begin{array}{l}\text { Alimentos ( } 8 / 33) \text {; plástico y hule ( } 1 / 14) ; \\
\text { minerales no metálicos (2/16: concreto; cal) }\end{array}$ \\
\hline
\end{tabular}

Fuente: elaboración propia. 
Samuel Ortiz Velásquez | La relación comercial de México con Estados Unidos y

China en el siglo XXI: efectos en la integración local del aparato productivo mexicano

Cuadro 3 Tipología (2003-2014) (Participaciones relativas promedio ponderadas)

\begin{tabular}{llllll}
\hline \multicolumn{1}{c}{ Agrupamientos } & Empleo & $\begin{array}{c}\text { Valor agregado } \\
\text { bruto }\end{array}$ & $\begin{array}{c}\text { Acervo de } \\
\text { capital }\end{array}$ & IED & $\begin{array}{l}\text { Ventas a } \\
\text { mdo nacional }\end{array}$ \\
\hline Total de la manufactura (220 i) & 100.00 & 100.00 & 100.00 & 100.00 & 100.00 \\
I. Desplazamiento parcial de EEUu (26 i) & 11.10 & 16.81 & 17.36 & 30.05 & 13.80 \\
I.A.Exportadoras (10 i) & 4.09 & 8.74 & 10.33 & 25.05 & 4.95 \\
I.B.Mercado interno (16 i) & 7.01 & 8.07 & 7.02 & 5.01 & 8.84 \\
II. Desplazamiento directo de EEUu (11 i) & 2.29 & 16.18 & 14.87 & 2.30 & 25.48 \\
II.A. Exportadoras (2 i) & 0.13 & 0.55 & 0.25 & 0.06 & 0.24 \\
II.B. Mercado interno (9 i) & 2.16 & 15.64 & 14.62 & 2.24 & 25.24 \\
III. Desplazamiento parcial de China (4 i) & 1.37 & 3.84 & 6.96 & 2.09 & 3.14 \\
III.A. Exportadoras (1 i) & 0.31 & 0.18 & 0.09 & 0.18 & 0.13 \\
III.B. Mercado interno (4 i) & 1.06 & 3.66 & 6.87 & 1.90 & 3.01 \\
IV. Desplazamiento directo de China (152 i) & 81.82 & 52.93 & 53.08 & 61.57 & 40.32 \\
IV.A. Exportadoras (62 i) & 32.83 & 22.87 & 22.49 & 26.80 & 12.51 \\
IV.B. Mercado interno (90 i) & 48.98 & 30.06 & 30.59 & 34.76 & 27.81 \\
V. Retirada de ambos (mdo interno) (14 i) & 2.63 & 9.34 & 5.59 & 2.88 & 13.32 \\
VI. China y EEuu no participan (13 i) & 3.26 & 2.30 & 2.86 & 1.10 & 4.04 \\
VI.A. Exportadoras (2 i) & 0.05 & 0.06 & 0.06 & 0.08 & 0.08 \\
VI. B. Mercado interno (11 i) & 3.22 & 2.24 & 2.80 & 1.02 & 3.96 \\
\hline
\end{tabular}

Fuente: elaboración propia con base en INEGI (2017).

El subgrupo I ha sido el más dinámico según el crecimiento del producto agregado, en su interior, las 10 industrias con vocación exportadora y muy alto tamaño de planta, crecieron al 4\%, dicho dinamismo se explicó en lo fundamental por el crecimiento de la productividad, altamente correlacionado con el crecimiento de la densidad de capital o dotación de capital fijo por trabajador (ver cuadro 4). Con ello, el crecimiento de la productividad en las industrias exportadoras dependientes de importaciones estadounidenses ha descansado en el dinamismo de la acumulación. En el subgrupo II de creciente presencia de importaciones de EEUU en contra de las chinas, destacan las nueve industrias orientadas al mercado nacional y determinadas por la industria petrolera, pues el producto y la productividad decrecieron a una tasa de $2.7 \%$, mientras la ocupación se estancó y los acervos netos decrecieron al 3\%.

Por otro lado, en términos generales, el subgrupo IV donde las importaciones chinas han desplazado a las estadounidenses, se conforma en general por industrias intensivas en trabajo y baja dotación de capital por trabajador. En su interior, las 62 industrias exportadoras crecieron a una tasa próxima al $2 \%$, fue un estilo de crecimiento predominantemente intensivo basado en el crecimiento de la productividad, pero más que en la adición de recursos (inversión), el crecimiento de ésta última se asienta al parecer en una mayor eficiencia en el uso de los recursos productivos. Por otro lado, las 90 industrias orientadas al mercado nacional han permanecido estancadas, presentando retroce- 
Cuadro 4 Indicadores de organización industrial (2003-2014) (coeficientes y tasas de crecimiento promedio anual)

\begin{tabular}{|c|c|c|c|c|c|c|c|}
\hline \multirow[t]{2}{*}{ Agrupamientos } & \multirow{2}{*}{$\begin{array}{c}\text { Acervo } \\
\text { neto } \\
\left(^{*}\right)\end{array}$} & \multirow{2}{*}{$\begin{array}{l}\text { Ocupa- } \\
\text { ción } \\
\left(^{*}\right)\end{array}$} & \multicolumn{2}{|c|}{$\begin{array}{l}\text { Dotación de capital } \\
\text { por ocupado }\end{array}$} & \multicolumn{2}{|c|}{$\begin{array}{l}\text { Productividad del } \\
\text { trabajo }\end{array}$} & \multirow{2}{*}{$\begin{array}{c}\text { Producto } \\
\text { agregado } \\
\left(^{*}\right)\end{array}$} \\
\hline & & & $(* *)$ & $(*)$ & $(* *)$ & $(*)$ & \\
\hline Total de la manufactura (220 i) & 0.2 & 0.4 & 778 & -0.2 & 711 & 0.7 & 1.1 \\
\hline $\begin{array}{l}\text { I. Desplazamiento parcial de EEUU } \\
\text { (26 i) }\end{array}$ & 2.5 & -0.6 & 1,212 & 3.2 & 1,077 & 3.5 & 2.8 \\
\hline I.A.Exportadoras (10 i) & 3.4 & 1.1 & 1,960 & 2.4 & 1,521 & 2.9 & 4.0 \\
\hline I.B.Mercado interno (16 i) & 1.1 & -1.7 & 777 & 2.8 & 818 & 3.1 & 1.3 \\
\hline $\begin{array}{l}\text { II. Desplazamiento directo de EEUU } \\
\text { (11 i) }\end{array}$ & -3.0 & -0.1 & 5,200 & -2.9 & 5,034 & -2.2 & -2.3 \\
\hline II.A. Exportadoras (2 i) & 6.2 & -2.1 & 1,477 & 8.6 & 3,050 & 11.0 & 8.6 \\
\hline II.B. Mercado interno (9 i) & -3.2 & 0.0 & 5,419 & -3.1 & 5,150 & -2.7 & -2.7 \\
\hline $\begin{array}{l}\text { III. Desplazamiento parcial de } \\
\text { China (4 i) }\end{array}$ & 1.5 & 1.8 & 3,988 & -0.3 & 1,996 & -0.1 & 1.7 \\
\hline III.A. Exportadoras (1 i) & 0.8 & 1.8 & 228 & -1.0 & 402 & 4.4 & 6.3 \\
\hline III.B. Mercado interno (3 i) & 1.5 & 1.8 & 5,095 & -0.3 & 2,466 & -0.3 & 1.5 \\
\hline $\begin{array}{l}\text { IV. Desplazamiento directo de } \\
\text { China (152 i) }\end{array}$ & -0.1 & -0.2 & 503 & 0.1 & 460 & 1.0 & 0.8 \\
\hline IV.A. Exportadoras (62 i) & 0.5 & 0.7 & 528 & -0.2 & 495 & 1.1 & 1.9 \\
\hline IV.B. Mercado interno (90 i) & -0.6 & -0.8 & 486 & 0.3 & 436 & 0.8 & 0.0 \\
\hline $\begin{array}{l}\text { V. Retirada de ambos (mdo inter- } \\
\text { no) (14 i) }\end{array}$ & -1.5 & -0.9 & 1,648 & -0.6 & 2,528 & 1.4 & 0.5 \\
\hline VI. China y EeUu no participan (13 i) & 0.5 & 1.9 & 669 & -1.4 & 500 & 1.0 & 3.0 \\
\hline VI.A. Exportadoras (2 i) & -3.6 & -3.9 & 1,014 & 0.4 & 934 & 5.7 & 1.5 \\
\hline VI. B. Mercado interno (11 i) & 0.6 & 2.0 & 664 & -1.4 & 494 & 1.0 & 3.0 \\
\hline
\end{tabular}

(*) Coeficiente promedio ponderado 2003-2014

(**) Tasa de crecimiento promedio anual 2003-2014

Fuente: elaboración propia con base en INEGI (2017).

sos en ocupación y expansión de los acervos, es un subgrupo que presenta serios obstáculos a la acumulación.

\subsection{Comercio exterior e integración local}

\subsubsection{Producto agregado y comercio exterior}

El crecimiento del producto entre 2003-2014 para el total de las industrias, guardó una asociación positiva con el crecimiento de las ex- portaciones a Estados Unidos y con el crecimiento de las importaciones totales, siendo más fuerte la asociación con el segundo indicador (ver cuadro 5). Por otro lado, las exportaciones a EEUU presentaron un coeficiente de correlación cercano a la unidad con las importaciones totales y estadounidenses. Es decir, los coeficientes de correlación ofrecen evidencia de que la industria mexicana presenta una integración comercial débil, pues las exportaciones estadounidenses operan como acelerador 
Samuel Ortiz Velásquez | La relación comercial de México con Estados Unidos y

China en el siglo XXI: efectos en la integración local del aparato productivo mexicano

del producto agregado y con más fuerza de las importaciones, por lo que el saldo neto para la integración local ha sido negativo.

A nivel de subgrupos, se verificaron coeficientes cercanos a la unidad concretamente en los dos agrupamientos altamente exportadores: I.A de 10 industrias altamente exportadoras donde las importaciones estadounidenses son más relevantes que las chinas y en el subgrupo IV.A de 62 industrias altamente exportadoras donde las importaciones chinas desplazan a las de EeUu. El subgrupo II.B. de 9 industrias orientadas al mercado nacional y determina- do por refinación de petróleo y aceites/grasas lubricantes, presentó coeficientes altos y ello apunta a una profundización de la organización industrial de la industria petrolera entre México y los eevu. Por su parte, en el subgrupo de 90 industrias orientadas al mercado nacional y con presencia de importaciones chinas, el crecimiento del producto no presentó una asociación con las exportaciones a EEUU, pero si presentó una asociación positiva con las importaciones, ello revela como los momentos de auge en las industrias orientadas al mercado nacional, no generan efectos relevantes para la

Cuadro 5 Coeficientes de correlación del producto agregado con indicadores clave (2003-2014)

\begin{tabular}{|c|c|c|c|c|c|}
\hline & \multicolumn{2}{|c|}{ TC del producto agregado } & \multicolumn{3}{|c|}{ TC de las exportaciones a EEUU } \\
\hline & $\begin{array}{c}\text { Exportacio- } \\
\text { nes a EeUU }\end{array}$ & $\begin{array}{l}\text { Importacio- } \\
\text { nes }\end{array}$ & $\begin{array}{l}\text { Importacio- } \\
\text { nes }\end{array}$ & $\begin{array}{l}\text { Importacio- } \\
\text { nes de eEuU }\end{array}$ & $\begin{array}{l}\text { Importacio- } \\
\text { nes de China }\end{array}$ \\
\hline & $(\mathrm{TC})$ & $(\mathrm{TC})$ & $(\mathrm{TC})$ & $(\mathrm{TC})$ & (TC) \\
\hline Total de la manufactura (220 i) & 0.276 & 0.570 & 0.846 & 0.789 & 0.377 \\
\hline I. Desplazamiento parcial de EEUu (26 i) & 0.744 & 0.892 & 0.491 & 0.361 & -0.250 \\
\hline I.A.Exportadoras (10 i) & 0.823 & 0.784 & 0.473 & 0.319 & -0.253 \\
\hline I.B.Mercado interno (16 i) & 0.311 & 0.288 & -0.020 & 0.011 & -0.294 \\
\hline II. Desplazamiento directo de EEUu (11 i) & 0.972 & 0.883 & 0.951 & 0.958 & 0.978 \\
\hline II.A. Exportadoras (2 i) & 0.689 & -0.120 & -0.519 & -0.288 & 0.040 \\
\hline II.B. Mercado interno (9 i) & 0.971 & 0.881 & 0.952 & 0.959 & 0.978 \\
\hline $\begin{array}{l}\text { III. Desplazamiento parcial de China } \\
\text { (4 i) }\end{array}$ & 0.816 & 0.648 & 0.491 & 0.436 & 0.246 \\
\hline III.A. Exportadoras (1 i) & -0.645 & 0.451 & -0.363 & -0.309 & 0.104 \\
\hline III.B. Mercado interno (3 i) & 0.838 & 0.633 & 0.569 & 0.624 & 0.287 \\
\hline $\begin{array}{l}\text { IV. Desplazamiento directo de China } \\
\text { (152 i) }\end{array}$ & 0.622 & 0.685 & 0.850 & 0.748 & 0.401 \\
\hline IV.A. Exportadoras (62 i) & 0.877 & 0.845 & 0.892 & 0.890 & 0.158 \\
\hline IV.B. Mercado interno (90 i) & 0.001 & 0.516 & 0.626 & 0.342 & 0.419 \\
\hline $\begin{array}{l}\text { V. Retirada de ambos (mdo interno) } \\
\text { (14 i) }\end{array}$ & -0.044 & 0.396 & 0.440 & 0.373 & -0.036 \\
\hline VI. China y EEUu no participan (13 i) & 0.460 & 0.662 & 0.479 & 0.460 & -0.487 \\
\hline VI.A. Exportadoras (2 i) & 0.454 & 0.221 & -0.068 & 0.259 & -0.302 \\
\hline VI. B. Mercado interno (11 i) & 0.384 & 0.705 & 0.534 & 0.477 & -0.588 \\
\hline
\end{tabular}

$\mathrm{TC}=$ Tasa de crecimiento interanual

Fuente: elaboración propia con base en INEGI (2017). 
Cuadro 6 Coeficientes de correlación del acervo de capital con indicadores clave (2003-2014)

\begin{tabular}{lccccc}
\hline & \multicolumn{3}{c}{ TC del acervo neto de capital } \\
& $\begin{array}{c}\text { Producto } \\
\text { agregado }\end{array}$ & $\begin{array}{c}\text { Exportacio- } \\
\text { nes de EEUU }\end{array}$ & $\begin{array}{c}\text { Importacio- } \\
\text { nes }\end{array}$ & $\begin{array}{c}\text { Importacio- } \\
\text { nes de China }\end{array}$ & IED \\
& (TC) & (TC) & (TC) & (TC) & (TCt-1) \\
\hline Total de la manufactura (220 i) & 0.902 & 0.034 & 0.288 & 0.072 & -0.098 \\
I. Desplazamiento parcial de EEUu (26 i) & 0.571 & 0.318 & 0.614 & 0.210 & 0.890 \\
I.A.Exportadoras (10 i) & 0.603 & 0.291 & 0.635 & 0.258 & 0.908 \\
I.B.Mercado interno (16 i) & 0.139 & -0.043 & -0.316 & -0.550 & 0.267 \\
II. Desplazamiento directo de EEUu (11 i) & 0.971 & 0.918 & 0.817 & 0.562 & 0.223 \\
II.A. Exportadoras (2 i) & 0.631 & 0.274 & 0.261 & 0.492 & 0.009 \\
II.B. Mercado interno (9 i) & 0.971 & 0.913 & 0.816 & 0.142 & 0.146 \\
III. Desplazamiento parcial de China (4 i) & 0.454 & 0.331 & 0.080 & -0.053 & -0.442 \\
III.A. Exportadoras (1) i) & 0.379 & -0.077 & 0.249 & 0.088 & -0.142 \\
III.B. Mercado interno (3 i) & 0.463 & 0.296 & 0.105 & -0.057 & -0.490 \\
IV. Desplazamiento directo de China (152 i) & 0.466 & 0.171 & 0.078 & -0.143 & 0.461 \\
IV.A. Exportadoras (62 i) & 0.505 & 0.547 & 0.281 & 0.347 & 0.478 \\
IV.B. Mercado interno (90 i) & 0.432 & -0.103 & -0.072 & -0.087 & 0.418 \\
V. Retirada de ambos (mdo interno) (14 i) & 0.382 & 0.085 & 0.515 & 0.331 & 0.220 \\
VI. China y EEu no participan (13 i) & 0.442 & 0.243 & 0.490 & 0.042 & -0.383 \\
VI.A. Exportadoras (2 i) & 0.190 & -0.095 & 0.017 & 0.000 & -0.043 \\
VI. B. Mercado interno (11 i) & 0.458 & 0.202 & 0.507 & 0.041 & -0.144 \\
\hline
\end{tabular}

$\mathrm{TC}=$ Tasa de crecimiento interanual.

Fuente: elaboración propia con base en INEGI (2017).

integración local, pues buena parte de su dinamismo se filtra al resto de mundo, vía una mayor demanda de importaciones.

\subsubsection{Acervos de capital netos y comercio exterior}

Para la industria en su conjunto se verificó una asociación positiva casi cercana a la unidad entre el crecimiento del acervo de capital neto y el crecimiento del producto agregado, lo cual fortalece la evidencia de que el acelerador es el determinante sistemático de la acumulación (ver cuadro 6). Los acervos mostraron una asociación positiva con las importaciones, lo cual puede apuntar a que, dado el alto componente importado en la oferta de bienes de capital, las importaciones complementan en parte a la inversión fija bruta total. Por otro lado, no se verificó una asociación entre el crecimiento de los acervos con las exportaciones y la IED. Ello se explica en parte porque no todos los flujos de IED tienen como destino la creación de capital, de hecho, como ha señalado Cepal (2016) aproximadamente un tercio de la IED en América Latina y el Caribe crea nuevo capital físico, mientras otro tercio se destina a fusiones y adquisiciones y el resto opera como fugas y perdidas de la IED (vía el desplazamiento de la inversión y el financiamiento local y de la inversión en activos financieros no vinculada a la formación bruta de capital). 
Samuel Ortiz Velásquez | La relación comercial de México con Estados Unidos y

China en el siglo XXI: efectos en la integración local del aparato productivo mexicano

En todos los agrupamientos se observó una asociación positiva entre producto y acervos de capital. Por otro lado, en los subgrupos altamente exportadores (I.A y IV.A), las tasas de crecimiento de los acervos de capital, guardaron una asociación positiva con las tasas de crecimiento de todos los indicadores del cuadro 6. Es decir, en éstos subgrupos las exportaciones estadounidenses fungen como un acelerador de la inversión, a su vez y en coherencia con la hipótesis, las importaciones (de bienes de capital e intermedios) también estimulan la acumulación, pues son cruciales para su actividad exportadora. La fuerte correlación positiva existente entre la IED y los acervos ofrece al- guna evidencia de que en éstas industrias con presencia de capital extranjero, la IED complementa a la inversión privada total.

En contraste, llama la atención que en los subgrupos orientados al mercado interno (I.B y IV.B,) el crecimiento de los acervos guardó una asociación negativa débil con las exportaciones de EEUU, pues al trabajar para el mercado interno, el dinamismo de los acervos se estimula por las condiciones de la demanda interna (i.e., por el crecimiento del producto). Por otro lado, los acervos también guardaron una asociación negativa con el crecimiento de las importaciones particularmente con las provenientes de China. El resultado es relevante y

Cuadro 7 Coeficientes de correlación de los insumos nacionales con indicadores clave (2003-2014)

\begin{tabular}{|c|c|c|c|c|}
\hline & \multicolumn{3}{|c|}{ Coeficiente de insumos nacionales } & \multirow{3}{*}{$\begin{array}{l}\text { TC importaciones } \\
\text { de China }\end{array}$} \\
\hline & $\begin{array}{l}\text { Producto } \\
\text { agregado }\end{array}$ & $\begin{array}{l}\text { Exporta- } \\
\text { ciones a }\end{array}$ & $\begin{array}{l}\text { Importa- } \\
\text { ciones de }\end{array}$ & \\
\hline & $(\mathrm{TC})$ & (TC) & $(\mathrm{TC})$ & \\
\hline Total de la manufactura (220 i) & 0.811 & -0.127 & -0.453 & -0.014 \\
\hline I. Desplazamiento parcial de eEuU (26 i) & 0.232 & 0.194 & -0.236 & 0.013 \\
\hline I.A.Exportadoras (10 i) & 0.261 & 0.177 & -0.148 & 0.061 \\
\hline I.B.Mercado interno (16 i) & -0.540 & -0.554 & -0.471 & 0.390 \\
\hline II. Desplazamiento directo de EEUu (11 i) & 0.061 & -0.026 & -0.017 & -0.181 \\
\hline II.A. Exportadoras (2 i) & 0.086 & 0.069 & -0.004 & -0.041 \\
\hline II.B. Mercado interno (9 i) & -0.007 & -0.097 & -0.077 & -0.249 \\
\hline III. Desplazamiento parcial de China (4 i) & -0.188 & -0.339 & 0.197 & 0.379 \\
\hline III.A. Exportadoras (1 i) & 0.011 & -0.124 & -0.063 & -0.184 \\
\hline III.B. Mercado interno (3 i) & -0.209 & -0.210 & 0.269 & 0.373 \\
\hline IV. Desplazamiento directo de China (152 i) & 0.064 & 0.080 & -0.799 & -0.039 \\
\hline IV.A. Exportadoras (62 i) & -0.179 & 0.215 & -0.655 & 0.036 \\
\hline IV.B. Mercado interno (90 i) & 0.224 & -0.193 & -0.778 & -0.116 \\
\hline V. Retirada de ambos (mdo interno) (14 i) & -0.001 & -0.127 & 0.573 & 0.115 \\
\hline VI. China y EeUu no participan (13 i) & -0.628 & 0.125 & -0.060 & -0.061 \\
\hline VI.A. Exportadoras (2 i) & 0.348 & 0.735 & -0.237 & 0.118 \\
\hline VI. B. Mercado interno (11 i) & -0.646 & 0.004 & 0.000 & -0.079 \\
\hline
\end{tabular}

$\mathrm{TC}=$ Tasa de crecimiento interanual

Fuente: elaboración propia con base en INEGI (2017). 
contribuye a fortalecer la hipótesis y los resultados de Ortiz Velásquez (2015), pues a diferencia de los grupos altamente exportadores, las industrias orientadas al mercado nacional se han visto amenazadas por la irrupción de importaciones (particularmente chinas) y ello desestimula su acumulación, en la medida en que las desplaza como proveedoras.

\subsubsection{Encadenamientos productivos}

internos y comercio exterior:

El grado de encadenamientos directos con proveedores locales se mide a través del coeficiente de insumos nacionales (in) o razón compras de insumos nacionales a producción bruta total, donde un aumento de la compra de insumos nacionales, indica la presencia y una mejora de encadenamientos con empresas nacionales (Smarzynska, 2002).

Para la industria en su conjunto, se asistió a una muy alta correlación entre el crecimiento del producto y el coeficiente de encadenamientos directos. Así mismo, se verificó una asociación negativa entre las tasas de crecimiento de las exportaciones a EeUu y el coeficiente de insumos nacionales y entre éste último y las importaciones chinas (ver cuadro 7). Es decir, se presenta evidencia de que las importaciones chinas están desplazando a proveedores locales en el mercado mexicano, contribuyendo con ello al debilitamiento de los encadenamientos productivos internos. La asociación negativa entre coeficiente de encadenamientos y crecimiento de las importaciones chinas está presente en casi todos los subgrupos sean exportadores u orientados al mercado nacional, siendo más fuerte en el caso de las industrias orientadas al mercado nacional, donde destaca el coeficiente de -0.778 que presentan las 90 industrias orientas al mercado nacional.
Es interesante señalar que, para la industria en su conjunto, no se verificó la existencia de una asociación lineal entre las tasas de crecimiento de las importaciones chinas y el empleo, pero si se verificó una débil asociación negativa en las 90 industrias orientadas al mercado nacional y que han experimentado una abrupta presencia de importaciones chinas.

\section{Conclusiones}

La crisis del aparato productivo mexicano que se ha profundizado desde 2001, se explica en parte por el tipo especial de integración comercial que presentan las manufacturas mexicanas, bajo la modalidad de crecimiento usualmente denominada neoliberal. Tal inserción se caracteriza por presentar bajos niveles de apropiación de valor agregado local y una acentuación de la dependencia importadora (de por si elevada durante la ISI), todo lo cual, en términos netos ha impactado adversamente sobre los encadenamientos productivos con proveedores locales al tiempo que ha inhibido la inversión y la generación de empleo formal.

En nuestra opinión la política macroeconómica e industrial (mesoeconómica) vigente se ha alineado y hecho funcional a la dinámica de las Cadenas Globales de Valor gobernadas por ET. En particular los periodos recurrentes de apreciación del tipo de cambio real y los programas que fomentan procesos de importaciones temporales para su posterior exportación (ITE), han generado fuertes incentivos para profundizar la dependencia importadora del aparato productivo mexicano. Cierto es que las importaciones de bienes de capital son cruciales para complementar la oferta total de bienes de inversión en economías como la mexicana. El tema es que, con la apertura económica, también se ha estimulado la entrada 
de importaciones prescindibles (v.gr., bienes de consumo final no duradero y algunos insumos intermedios), todo lo cual ha tenido efectos diferenciados en el aparato productivo nacional. Por una parte, ha sido favorable al grupo selecto de industrias exportadoras altamente fomentadas a través de diversos instrumentos de apoyo y que participan en la dinámica de las CGV (electrónica, autopartes, automotriz) y ha sido perjudicial para el universo de industrias orientadas al mercado nacional productoras típicas de bienes de consumo y de intermedios, afectadas por el enfoque horizontal de política industrial vigente desde 1988.

En el documento se demostró cómo el ingreso de China a la OMC en 2001 sólo profundizó la dependencia importadora del aparato productivo mexicano. Entre otras cosas, desde la década pasada China ha desplazado directamente a los Estados Unidos como principal proveedor de importaciones en 152 clases industriales que funcionan en México (de un universo de 220 clases). De éstas, 62 industrias están orientadas a las exportaciones, destacan clases que conforman a las industrias de insumos textiles, textiles, cuero, maquinaria y equipo, eléctricos, computadoras y siete industrias de autopartes. En breve, la industria de autopartes se encadena fuertemente hacia adelante con la industria productora de automóviles; considerando que el principal mercado de destino de las exportaciones mexicanas son los Estados Unidos, bien se puede sostener que China se "cuela" al mercado estadounidense de forma directa y de forma indirecta vía el creciente contenido importado chino presente en los automóviles y camionetas ensamblados en México. Ello revela la emergencia de una compleja organización industrial que se ha establecido entre las citadas industrias con China y con EEUu y sus efectos adversos para la integración local.
En el subgrupo de abrupta presencia china se localizaron también 90 industrias que trabajan para el mercado interno, que presentan fuertes encadenamientos productivos internos y que son relevantes en generación de empleo, destacan clases que perteneces a las industrias del vestido, calzado, papel, plástico y hule, química metálicas básicas, electrónica-eléctricos, muebles. Tales industrias han sufrido por la política económica vigente que favorece la entrada masiva de importaciones particularmente chinas, con implicaciones negativas en términos de crecimiento del producto, acervos y encadenamientos productivos.

Por otro lado, se identificaron un grupo de 26 industrias fuertemente articuladas hacia atrás y hacia adelante con la economía de los EEUU. El subgrupo ha sido el más dinámico en términos de ritmos de expansión del acervo de capital, la productividad y el crecimiento del producto agregado y está determinado por la clase productora de automóviles y camionetas, la principal ganadora del proceso de integración con América del Norte. La clase productora de automóviles comparte una organización industrial dependiente de importaciones y una débil capacidad de generación de empleo, pues es una industria intensiva en capital.

Ante la renegociación del trcan, México debería leer el escenario internacional como una oportunidad que le puede permitir lograr cierta autonomía de los Estados Unidos y con ello, impulsar una nueva estrategia de crecimiento que ponga el acento en las industrias generadoras de empleo, orientadas al mercado nacional y de fuertes encadenamientos productivos, que sea capaz de reducir la dependencia importadora y de preparar a sus industrias para que incursionen en exportaciones a otros mercados. Tal empresa no es sencilla en el corto plazo, considerando que la variable política no está alineada a las circunstancias. 
La formulación de una nueva estrategia pasa por articular la política macroeconómica al logro de objetivos tales como: la mejora en las condiciones de acceso al crédito productivo con énfasis en las industrias de menor tamaño; el dinamismo de la demanda interna; un tipo de cambio coherente con una estrategia de crecimiento de largo plazo, que estimule la entrada de importaciones no prescindibles (v.gr., bienes de capital) y que restrinja la entrada de importaciones prescindibles para reactivar la proveeduría local.

Se debe modificar el enfoque horizontal de política industrial, priorizando a las actividades clave en generación de empleos y encadenamientos. Actualmente buena parte de los apoyos gubernamentales se dirigen a actividades de nivel tecnológico medio-alto de alta dotación capital por trabajador y una fuerte presencia de IED que sigue motivaciones de rentabilidad privada y que usualmente genera una baja integración local, mientras, buena parte de las industrias generadas de empleo y encadenamientos se mantienen al margen de los apoyos.

A nivel micro, el análisis demostró que las clases industriales desfavorecidas de la estrategia actual, presentan un potencial de crecimiento en el corto plazo. Efectivamente, siguiendo a López (2008) en términos generales, las industrias mexicanas presentan muy altos márgenes de capacidad ociosa (en promedio el margen de capacidad ociosa en las industrias orientadas al mercado nacional se ha situado en $21 \%$ desde 2007 ), por lo cual, una estrategia de corto plazo no implica necesariamente llevar adelante esfuerzos de inversión considerables, ello puede permitir dar prioridad a inversiones selectas en industrias generadoras de empleo y encadenamientos. Por otro lado, parece haber visos positivos por parte de algunas cámaras empresariales sobre la necesidad de elevar los salarios reales en la industria, como un factor dinamizador de la demanda interna y por intermedio de ella, de la rentabilidad. ?

\section{Bibliografía}

Banco Mundial (2017), World Development Indicators. Recuperado de < https://data.worldbank.org/ data-catalog/world-development-indicators>

Comisión Económica para América latina (cepal) (2016), La Inversión Extranjera Directa en América Latina y el Caribe 2016, Santiago de Chile, Cepal.

Dussel Peters, E (2000), Polarizing Mexico. The impact of the liberalization strategy, Usa, Lynne Rienner Publisher.

Dussel Peters, E. (2003a), "Ser maquila o no ser maquila, ¿es ésa la pregunta?”, Comercio exterior, vol. 53, núm. 4, México, Bancomext, abril.

Dussel Peters, E. (2003b), "El debate en torno a la competitividad: conceptos e implicaciones de política”, en Dussel Peters Enrique (coord.), Perspectivas y retos de la competitividad en México, México Unam-Canacintra.

Dussel Peters, E. y K. Gallagher (2013), "El huésped no invitado del trCan: China y la desintegración del comercio en América del Norte", Revista de la CEPAL, núm. 110, Santiago de Chile, agosto.

Dussel Peters, E. y S. Ortiz Velásquez (2016), “El Tratado de Libre Comercio de América del Norte, ¿contribuye China a su integración o desintegración?”, en Dussel Peters Enrique (coord.), La nueva relación comercial de América Latina y el Caribe con China, ¿integración o desintegración regional?, México, Red alc-China y Cechimex unam.

Esser, K., W. Hillebrand, D. Messner y J. MeyerStamer (1999), "Competitividad sistémica Nuevo desafío para las empresas y la política”, en EssER Klaus (edit.), Competencia global y libertad de acción nacional. Nuevo desafio para las empresas, el Estado y la sociedad, Caracas, Nueva Sociedad e Instituto Alemán de Desarrollo.

FajnzyLber, F. (1980), "Las empresas transnacionales 
Samuel Ortiz Velásquez | La relación comercial de México con Estados Unidos y China en el siglo XXI: efectos en la integración local del aparato productivo mexicano

y el desarrollo industrial en México", en Fajnzylber Fernando, Industrialización e internacionalización de América Latina, México, El Trimestre Económico y FCE.

Fujil Gambero, G. y M. García Ramos (2016), "Las exportaciones de México, Corea y China como generadoras de divisas y de ingreso interno", Revista de Economía Mexicana, núm. 1, México, Facultad de Economía de la UNAM, anuario.

Gerefri, G. (2001), "Las cadenas productivas como marco analítico para la globalización", Problemas del Desarrollo, vol. 32, núm. 125, México, IIEcUNAM, abril-junio.

Instituto Nacional de Estadística y Geografía (INEGI) (2016a), Sistema de Clasificación Industrial de América del Norte, México 2007, SCIAN México 2007-Sistema de Clasificación Industrial de América del Norte, México 2002, sCIAN México 2002. Recuperado de < http://www.inegi.org.mx/est/contenidos/proyectos/scian/presentacion.aspx $>$

INEGI (2016b). Tabla de correlación entre la Tarifa de la Ley de los Impuestos Generales de Importación y de Exportación y el Sistema de Clasificación Industrial de América del Norte TIGIE - SCIAN. Recuperado de $<$ http://www3.inegi.org.mx/sistemas/clasificaciones/tigie/tigie.aspx $>$

INEGI (2017), Banco de Información Económica. Recuperado de <http://www.inegi.org.mx/sistemas/ bie/>

Koopman, R., Z. Wang y S.J. Wei (2014). "Tracing Value-Added and Double Counting in Gross Exports", American Economic Review, vol. 104, no. 2, American Economic Association, February.
Lall, S. y J. Weiss (2005), "China’s Competitive Threat to Latin America: An Analysis for 19902002", Oxford Development Studies vol. 33, no. 2.

LÓPEZ, J. (2008), "Una reconsideración de las perspectivas económicas de México", Economia e Sociedade, vol. 17, número especial, Brasil, Instituto de Economia da Universidade Estadual de Campinas, diciembre.

Moreno-Brid, J. C. (1999), Reformas macroeconómicas $e$ inversión manufacturera en México, Serie reformas económicas no. 47, México, CEPAL.

Ortiz Velásquez, S. (2015), Inversión en la industria manufacturera mexicana y sus determinantes mesoeconómicos: 1988-2012 (Tesis doctoral). Universidad Nacional Autónoma de México, México.

Smarzynska, B. (2002), Spillovers from Foreign Direct Investment through Backward Linkages: Does Technology Gap Matter?, Mimeo, World Bank.

Timmer, M. P., A. A. Erumban, B. Los, R. Stehrer y G. J. de Vries (2014). "Slicing Up Global Value Chains". Journal of Economic Perspectives, vol. 28, no. 2, American Economic Association, Spring, pp. 99-118.

United Nations Conference on Trade and DevelOPMENT (UNCTAD) (2011), World Investment Report 2011: Non-Equity Modes of International Production and Development, New York and Ginebra, United Nations, pp. 123-177.

Valenzuela Feijóo, J. (2014). Teoría general de las economías de mercado: tomo II, funcionamiento $y$ dinámica, México, Facultad de Economía de la UNAM. 